\title{
Insulados e não democráticos: a (im)possibilidade do exercício da social accountability nos Tribunais de Contas brasileiros
}

\author{
Diones Gomes da Rocha 1 \\ Robson Zuccolotto 1 \\ Marco Antonio Carvalho Teixeira ${ }^{2}$ \\ 1 Universidade Federal do Espírito Santo / Programa de Pós-graduação em Contabilidade, Vitória / ES - Brasil \\ ${ }^{2}$ Fundação Getulio Vargas (FGV EAESP) / Programa de Pós-graduação em Administração Pública e Governo, São Paulo / SP - Brasil
}

Este artigo tem por objetivo analisar a permeabilidade dos Tribunais de Contas (TCs) brasileiros à sociedade, por meio de 3 perspectivas: a) transparência dos portais; b) transparência da atividade de fiscalização; e c) participação cidadã. Para tanto, foi estruturado um roteiro de observações, a partir de recomendações de organismos internacionais, e foram coletadas informações dos 32 TCss existentes no Brasil. Em seguida, foram elaborados mapas perceptuais para cada uma das perspectivas analisadas, por meio da técnica de escalonamento multidimensional. As evidências sugerem que os TCs não são transparentes, o que limita a social accountability, e são muito resistentes à participação social, limitando-se a disponibilizar os mecanismos de ouvidoria, portal da transparência e serviço de atendimento ao cidadão. Essas práticas evidenciam que os TCs são, ainda, muito insulados, burocratizados e, apesar de terem um relevante papel no contexto republicano, pouco democráticos. Identificou-se, entretanto, forte influência da Lei de Responsabilidade Fiscal (LRF) e da Lei de Acesso à Informação (LAI) sobre os TCs. Isso pode significar futuras mudanças, ainda que incrementais, na direção da atuação dos TCs como fortes aliados para o aprimoramento da accountability vertical.

Palavras-chave: social accountability; tribunais de contas; transparência.

\section{Aislados y antidemocráticos: la (im)posibilidad de ejercer la social accountability en los tribunales de cuentas brasileños}

Este artículo examina la permeabilidad de los tribunales decCuentas (TC) brasileños a la sociedad, y si dichos tribunales han actuado de forma que facilite el ejercicio del control social sobre la administración pública. La técnica de escalonamiento multidimensional se utilizó para la construcción de mapas perceptuales en tres dimensiones, elaborados a partir de informaciones recolectadas de los 32 TC existentes en Brasil. Las evidencias sugieren que los TC son todavía poco permeables a la sociedad y poseen pocos mecanismos para auxiliar o facilitar el control ciudadano. Se constató, además, una limitación de medios para la participación social, que se reducen, básicamente, a la oidoría, al portal de transparencia y al servicio de atención al ciudadano. Se identificó, sin embargo, una fuerte influencia de la Ley de Responsabilidad Fiscal y de la Ley de Acceso a la Información sobre los TC. Esto puede significar cambios futuros, aunque incrementales, en la dirección de la actuación de los TC como fuertes aliados para el perfeccionamiento de la accountability vertical.

Palabras clave: control social; tribunales de cuentas; transparencia.

\section{Insulated and undemocratic: the (im)possibility of social accountability in Brazilian courts of accounts}

This article examines the transparency of the Brazilian Courts of Accounts to citizens, andwhether these Courts have acted in a way that facilitates social accountability over public administration. The multidimensional scaling technique was used to determine the integrity of the 32 Courts of Accounts in Brazil. Evidence suggests that Brazilian Courts of Accounts are still not transparent to society and count on few mechanisms to help and facilitate citizen control. Evidence also shows that the means of social participation is limited, and represented by the Ombudsman, the Transparency Web Portal, and the Citizen Assistance Service. However, this study identified that the Fiscal Responsibility Law (LRF) and the Access to Information Law (LAI) had a strong influence on the Courts of Accounts. Although gradual, these elements can lead to future changes in terms of an increasingly prominent role of the Courts of Accounts as strong allies in the process of enhancing vertical accountability.

Keywords: social accountability; courts of accounts; transparency. 


\section{INTRODUÇÃO}

A representação (democrática) é um modo de participação política que pode ativar uma variedade de formas de controle e de supervisão por parte dos cidadãos, não se limitando a ser um esquema de delegação (democracia eleitoral), mas um processo político que conecta a sociedade às instituições (Estado). Esses controles ininterruptos fazem parte de um processo constitutivo mais amplo de accountability dos governantes (políticos eleitos ou burocratas ${ }^{1}$ ) para garantir que atuem em prol do interesse da sociedade (Urbinati, 2006).

Apesar do termo accountability não possuir uma tradução convencionalizada para o português, seu sentido foi amplamente debatido por autores como O'Donnell (1998) e Przeworski, Stokes, e Manin (1999), entre outros. De modo geral, tais autores estabelecem que accountability se relaciona à obrigatoriedade dos representantes prestarem contas ao povo, sendo esse processo caracterizado por 3 estágios: a) informação (transparência); b) justificação; e c) sanção.

Adicionalmente, O’Donnell (1998) classificou as formas de accountability como vertical e horizontal, relacionando a primeira às eleições e à participação social e a segunda às diversas instâncias de controles institucionais durante os mandatos, como o controle parlamentar, o controle judicial, o controle administrativo-procedimental e a social accountability, entre outros.

Devido ao caráter romano do ordenamento jurídico brasileiro, os controles judicial e administrativo-procedimental são exercidos por instituições seculares, com características predominantemente burocráticas, as quais limitam a efetivação da social accountability, inibindo as transformações democráticas imaginadas pelo constituinte originário na Constituição da República Federativa do Brasil (CF, 1988) e distanciando-as do efetivo sentido da representação democrática. Apesar desses limites, tais órgãos de accountability horizontal acabam desempenhando um relevante papel republicano, dado que funcionam como pesos e contrapesos diante de outros poderes.

Dentre essas instituições se encontram os tribunais de contas (TCs), caracterizados como instituições de controle administrativo-procedimental e detentores de um importante papel republicano no contexto nacional e subnacional brasileiro. Entretanto, quando se trata de seu caráter democrático, ou mais especificamente de representação democrática, há um debate sobre o desenvolvimento institucional desses órgãos e de suas transformações democráticas, que apontam limitações nesse processo.

Loureiro, Teixeira, e Prado (2008) e Rocha e Zuccolotto (2017) argumentam que o desenvolvimento institucional dos TCs foi incremental e sua ocorrência é mais influenciada por fatores externos do que por transformações derivadas das práticas de gestão do próprio órgão. Adicionalmente, Rocha (2017) identificou que, apesar dos avanços institucionais, os TCs ainda parecem estar distantes do que se espera de tais órgãos de controle externo quando se considera o verdadeiro sentido da representação democrática. Além disso, os autores supracitados apontam que fatores como clientelismo, patrimonialismo, corporativismo e insulamento burocrático fazem com que o desenvolvimento institucional desses órgãos seja incremental, dada a existência das forças de resistência e de resiliência. Isso faz com que persista, ao menos em parte, um conflito entre burocratização e democratização.

Dado o poder das forças de resistência, esses órgãos podem tornar-se uma espécie de panóptico (Bentham, 2008), ou seja, aquele que tudo vê, mas que não pode ser visto, contrariando frontalmente o

${ }^{1}$ Para maiores considerações sobre os atores políticos em uma democracia ver Weber (2011). 
sentido da democracia. Ainda que o próprio Bentham (2008) tenha apontado como solução submeter esses órgãos a supervisões periódicas da sociedade, tal solução não colocaria Estado e sociedade em interação contínua, como preconiza o conceito de representação democrática. Assim, a transparência e a efetiva supervisão continuada da sociedade são condições essenciais para que esses órgãos não se tornem cada vez mais ensimesmados e burocratizados, distanciando-se da sociedade e contrariando os preceitos democráticos.

Assim, o controle da burocracia pública é uma condição essencial para o bom funcionamento das democracias, pois, segundo Olivieri (2011), a burocracia pública não é apenas um conjunto de funcionários públicos e de processos administrativos, mas um dos fundamentos do exercício do poder estatal e do governo democrático. Além de ter muito poder, a burocracia pública sempre procura aumentálo e sua principal ferramenta para fazê-lo é a manutenção do segredo acerca de seus conhecimentos e suas intenções, sendo o poder democrático a única forma de contrapô-lo (Weber, 2012).

No Brasil, os estudos seminais sobre a burocracia não tiveram por foco a relação entre burocracia e democracia, mas entre burocracia e formação do Estado (Olivieri, 2011). Entretanto, estudos mais recentes, como Loureiro, Abrucio, e Pacheco (2010) e Cavalcante e Lotta (2015), retomaram a discussão da relação entre burocracia e democracia, buscando a compreensão sobre sua composição, seu funcionamento e sua relação com os políticos eleitos e a democracia.

Se, por um lado, os TCs se mostram fundamentais para a democracia, por outro, podem, dadas as suas características de dominação racional-legal, ameaçar a própria democracia, escondendo seus conhecimentos e suas intenções. Por isso, é fundamental que esses órgãos sejam transparentes e tenham canais que permitam à sociedade exercer a social accountability, fortalecendo a democracia e submetendo a burocracia a controles e responsabilização.

A partir desse quadro teórico analítico, o objetivo geral deste estudo foi analisar a permeabilidade dos TCs brasileiros à sociedade, por meio de 3 perspectivas: a) transparência dos portais; b) transparência da atividade de fiscalização; e c) participação cidadã. O sentido de permeabilidade adotado neste estudo se refere às práticas adotadas pelos TCs que permitam à sociedade exercer controles sobre essas instituições, seja por meio do acesso às informações desses órgãos ou pela existência de espaços institucionais onde a sociedade civil organizada possa participar na proposição de agenda, na fiscalização, nos controles e nas decisões.

Além desta introdução, este artigo tem 4 partes: a) a primeira traz uma revisão de literatura, para situar a discussão sobre a baixa democratização das instituições de accountability no Brasil; b) a segunda trata dos aspectos metodológicos; c) a terceira apresenta os resultados das análises; e d) a quarta traz as conclusões e considerações finais da pesquisa.

\section{DEMOCRACIA E INSTITUIÇÕES DE ACCOUNTABILITY NO BRASIL}

No século XVIII, a democracia representativa se pautava pelo argumento de que o sentido da representação se encontrava em refrear a democracia e construir um governo limitado e, consequentemente, responsável. Entretanto, a ideia de governo representativo como intrinsecamente singular produziu duas escolas distintas de pensamento que podem ser definidas, respectivamente, como um modelo eleitoral de democracia e um modelo representativo (Urbinati, 2006).

A primeira dessas escolas endossava uma visão de representação que se combinou ao elitismo nas instituições políticas (que consistia no domínio da competência) e a legitimação popular (que 
consistia no domínio do consentimento). Nessa visão, a representação se funda no princípio da divisão do trabalho e em uma seleção funcional de expertise que ganhou expressão em atores como Michels (1915), Mosca (1980), Pareto (1979), Schumpeter (1961), entre outros.

A segunda escola de pensamento, como destacado por Urbinati (2006), era explicitamente democrática e visava a evitar a concentração da fonte de legitimação nas instituições estatais e à redução do consentimento popular a um ato de autorização. Nessa visão, a representação se funda na teoria do consentimento, que vê a eleição como a expressão do direito de participar em algum nível da produção das leis e não como um método de transferência das preferências idiossincráticas das pessoas para profissionais e políticos selecionados. Essa corrente tem entre seus principais ícones autores como Condorcet (1968) e Paine (2011).

A partir dessa compreensão, autores como Manin (1997), Pitkin (1967) e Urbinati (2006) superaram o conceito liberal de democracia e retomaram a defesa da democracia representativa, argumentando que ela é mais do que a democracia eleitoral, destacando que as eleições podem produzir o governo responsável, mas não o governo representativo. Como assevera Urbinati (2006), a representação (política) não pode ser reduzida a um contrato (de delegação), firmado por meio das eleições, tampouco reduzida à nomeação de legisladores como substitutos do soberano ausente, uma vez que sua natureza consiste em ser constantemente recriada e dinamicamente ligada à sociedade.

Para a autora, a representação é um modo de governo original que não exclui a participação, dado que o oposto da representação não é a participação, mas a exclusão da representação. Além disso, ao contrário do caráter minimalista da democracia liberal, a representação visa a evitar a concentração da fonte de legitimação nas instituições estatais e à redução do consentimento popular em um único ato de autorização, ou seja, ao momento do voto.

Nesse sentido, Urbinati (2006) destaca que a representação é uma forma de participação política que pode ativar uma variedade de modos de controle e de supervisão por parte dos cidadãos. Assim, em vez de um esquema de delegação (democracia eleitoral), a representação é um processo político que conecta sociedade e instituições (Estado), já que na democracia representativa o povo soberano delega poder ao representante, mas também tem o poder negativo de destituí-lo.

Entretanto, para que esse poder negativo possa ser exercido, os desenhos institucionais das democracias são fundamentais ou, dito de outra forma, os espaços institucionais onde se exerce a democracia serão os definidores do nível de democracia de um país (Bobbio, 2000). Para esse autor, o nível de desenvolvimento de uma democracia não pode ser medido pelo número de sujeitos que têm direito de participar nas decisões que lhe dizem respeito, mas nos espaços onde podem exercer tal direito.

A existência desses espaços reforçam os controles dos governantes, que, de acordo com Arantes, Loureiro, Couto, e Teixeira (2010), constituem uma dimensão crucial em uma ordem democrática e devem ser exercidos tanto sobre os políticos eleitos como sobre a burocracia pública.

Os modos como esses controles são exercidos são denominados accountability, que, em geral, pode ser entendida como a obrigação de uma pessoa, organização ou grupo prestar contas de suas ações perante um terceiro (autoridade, sociedade etc.), justificá-las e sofrer sanções em caso de má conduta, ou receber compensações, em caso contrário (Bovens, Goodin, \& Schillemans, 2014).

Além do conceito, as formas de accountability são amplamente discutidas na literatura por autores como Przeworski et al. (1999) e Schedler (1999). Neste estudo, utilizou-se a classificação proposta por O’Donnell (1998), que distingue a accountability em 2 eixos: a) vertical; e b) horizontal. Enquanto 
a primeira se processa por meio do processo eleitoral e das instâncias participativas existentes na sociedade, a segunda se processa, sobretudo, por meio das instituições estatais, as quais, no Brasil, ainda guardam muitas características do período de sua criação, sobretudo de burocratização e insulamento.

A manutenção dessas características e os poucos avanços institucionais observados nesses órgãos (Loureiro et al., 2008; Rocha \& Zuccolotto, 2017) se devem, em parte, ao poder dessa burocracia, que, segundo Weber (2012), é muito grande e sempre se procura aumentá-lo, sendo uma das principais ferramentas de tal burocracia a manutenção do segredo acerca de seus conhecimentos e suas intenções. Para o referido autor, a administração burocrática sempre exclui o público.

Assim, essas instâncias institucionais acabam tornando-se pouco permeáveis aos mecanismos de accountability vertical, reproduzindo o modelo do panóptico (Bentham, 2008), ou seja, aquele que tudo vê, mas que não pode ser visto. Bentham (2008), no entanto, propunha que esse controlador fosse submetido a inspeções regulares por parte da sociedade, o que não se tem observado ao estudar as instituições de accountability horizontal no Brasil.

Esse tipo de inspeção é limitado porque, em geral, as práticas de social accountability são reguladas pelos órgãos burocráticos. Esse tipo de accountability, que, de acordo com Peruzzotti e Smulovitz (2002), é um mecanismo de controle vertical, mas não eleitoral, das autoridades políticas tem por objetivo monitorar o comportamento dos funcionários públicos, expor e denunciar atos ilegais e ativar as operações das agências horizontais de controle. Para esses autores, a social accountability é de vital importância para a democracia, pois é aquela que vai além do momento do voto.

No Brasil, esse tipo de accountability ainda se encontra em desenvolvimento e tem sido expresso por organismos como conselhos, orçamentos participativos etc. Mais recentemente, um modo de participação que tem assumido protagonismo consiste nas práticas de coprodução do controle. Tais estudos se fundamentam, sobretudo, no trabalho seminal de Marschall (2004) e expressam novas possibilidades de participação na produção, na implementação e no controle de políticas e bens públicos.

Nesse contexto, apesar dos avanços em busca do sentido teórico da represenação, as características do modelo liberal de democracia se tornam evidentes e parecem enraizadas na prática das instituições brasileiras, sobretudo daquelas de accountability horizontal, historicamente insuladas e burocratizadas.

Dentre essas instituições de controle horizontal se destacam os TCs, espaços institucionalizados cujo objetivo é assegurar a boa governança dos recursos públicos. Os TCs surgiram no Brasil na transição da Monarquia para a República, com a criação do Tribunal de Contas da União (TCU), em 1891 (Loureiro, Teixeira, \& Moraes, 2009) tiveram suas competências reforçadas e/ou ampliadas a partir da CF (1988) e da Lei de Responsabilidade Fiscal (LRF).

Recentemente, sob a égide das transformações democráticas, esses TCs passaram a defender práticas associadas ao conceito de representação democrática, como transparência e controle social. No entanto, estudos apontam que, apesar dos avanços nas competências, tais órgãos de controle avançaram muito pouco em termos institucionais (Loureiro et al., 2009), apesar de existirem avanços incrementais.

Esses autores apontam, ainda, que aspectos de resistência aos avanços institucionais são expressivos e que os avanços decorreram, em sua maioria, de fatores relacionados à conjuntura crítica (sobretudo advinda de pressões externas). Destacam, por fim, traços marcantes de clientelismo e patrimonialismo, além de insulamento burocrático e baixa transparência. Rocha e Zuccolotto (2017) acrescentam que essa resiliência é fortalecida pela predominância de associações de categorias dos próprios TCs, 
como o Instituto Rui Barbosa e a Associação dos Membros dos Tribunais de Contas do Brasil, os quais acabam atuando como um elemento de resistência aos avanços democráticos desses órgãos.

Diante do quadro exposto, há evidências de que tais instituições de accountability horizontal mantêm as características da burocracia weberiana, concentrando muito poder e, contrariamente aos pressupostos de visibilidade da democracia representativa, mantendo seus atos e suas intenções sob sigilo e impedindo, assim, tanto o controle exercido pelos políticos eleitos quanto o controle exercido pelo povo soberano sob atos praticados pelos TCs. Essa burocratização, caso exista, compromete a relação circular entre estado e sociedade e desvincula sociedade e instituições, como destaca Urbinati (2006), comprometendo a democracia.

\section{METODOLOGIA DA PESQUISA}

Para atingir os objetivos propostos, realizou-se uma pesquisa exploratória na qual, inicialmente, foi elaborado um roteiro de observações para os TCs brasileiros, considerando, nas palavras de Zuccolotto e Teixeira (2019), 3 perspectivas analíticas: a) transparência dos portais; b) transparência da atividade de fiscalização; e c) participação cidadã. Essas perspectivas foram construídas considerando o que estabelecem as normas e melhores práticas internacionais formuladas pela Organização Internacional de Entidades de Fiscalização Superiores (International Organization of Supreme Audit Institutions [INTOSAI], 1977) e pela Organização Latino-Americana e do Caribe de Entidades Fiscalizadora Superiores (Organización Latinoamericana y del Caribe de Entidades Fiscalizadoras Superiores [OLACEFS], 2014), além da International Budget PartnerShip (IBP, 2015) e das normas brasileiras que regulam a transparência fiscal e o acesso à informação pública - LRF e Lei de Acesso à Informação (LAI).

A Tabela 1 mostra as perspectivas e a quantidade de itens que compõem cada uma delas. $\mathrm{O}$ formulário de observação foi composto por 78 itens, cujas respostas consistem em sim ou não, sendo que $35,9 \%$ dos itens se relacionam à participação cidadã, $53,8 \%$ à transparência da atividade de fiscalização e $10,3 \%$ à transparência dos portais.

\section{TABELA 1 PERSPECTIVAS DE ANÁLISE E QUANTIDADE DE ITENS OBSERVADOS}

\begin{tabular}{|c|c|c|c|}
\hline Perspectivas & Variáveis & Itens & $\%$ \\
\hline $\begin{array}{l}\text { Transparência } \\
\text { dos portais }\end{array}$ & $\begin{array}{l}\text { Disponibilidade de página oficial na internet } \\
\text { Atualização } \\
\text { Navegabilidade } \\
\text { Interatividade } \\
\text { Conteúdo }\end{array}$ & 8 & 10,3 \\
\hline $\begin{array}{c}\text { Transparência } \\
\text { da atividade de } \\
\text { fiscalização }\end{array}$ & $\begin{array}{l}\text { Disponibilidade de informação institucional } \\
\text { Informação sobre o ciclo de auditoria } \\
\text { Disponibilidade de informação de ministros/conselheiros } \\
\text { Disponibilidade de informação sobre a gestão financeira e orçamentária }\end{array}$ & 42 & 53,8 \\
\hline
\end{tabular}




\begin{tabular}{|c|c|c|c|}
\hline Perspectivas & Variáveis & Itens & $\%$ \\
\hline \multirow{7}{*}{$\begin{array}{l}\text { Participação } \\
\text { cidadã }\end{array}$} & Participação na designação de ministros/conselheiros & \multirow{6}{*}{28} & \multirow{6}{*}{35,9} \\
\hline & Participação na elaboração do plano de auditoria/fiscalização & & \\
\hline & Participação no processo de auditoria/fiscalização & & \\
\hline & Participação no acompanhamento de recomendações/determinações & & \\
\hline & Canais de atenção ao cidadão & & \\
\hline & Prestação de contas/relatório de atividades & & \\
\hline & Total & 78 & 100 \\
\hline
\end{tabular}

Fonte: Elaborada pelos autores.

A perspectiva transparência dos portais avalia, por exemplo, a existência do portal, seu período de atualização, sua navegabilidade, sua interatividade e seu conteúdo. A perspectiva transparência da atividade de fiscalização avalia a conformidade de itens relativos a informações institucionais, ao ciclo de auditoria, a informações financeiras e orçamentárias, além de informações sobre ministros/conselheiros. A perspectiva participação cidadã avalia aspectos relacionados aos espaços de participação dos cidadãos no processo de escolha de conselheiros, na elaboração de planos de auditoria e no acompanhamento de recomendações/determinações advindas das auditorias realizadas.

Antes de qualquer procedimento de observação, o formulário completo foi validado junto a especialistas da Fundação Getulio Vargas (FGV) de São Paulo, do TCU, da Universidad de Valladolid, da Espanha, e da Universidade do Minho, de Portugal, com a finalidade de verificar a aderência das perguntas formuladas ao objeto da pesquisa.

\subsection{Coleta e organização dos dados}

De posse do formulário de observação, as 78 perguntas foram respondidas a partir de consulta direta da página na internet de cada um dos $32^{2}$ TCs brasileiros. Durante a consulta foram anotadas todas as observações julgadas importantes, tais como dificuldades encontradas para acesso à informação, página fora do ar ou inexistente, demora de acesso à página etc. Para garantir a fidedignidade da coleta, cada página consultada foi capturada e armazenada com auxílio do software Zotero (Corporation for Digital Scholarship, n.d.), um assistente de pesquisa pessoal.

A coleta de dados da primeira fase empírica foi realizada entre 19 de dezembro de 2016 e 30 de janeiro de 2017. Todas as perguntas foram estruturadas de modo similar, ou seja, perguntas diretas cuja resposta é dicotômica, limitando-se a sim ou não.

\subsection{Análise dos dados}

Além da estatística descritiva dos dados, adotou-se a técnica exploratória multivariada de escalonamento multidimensional (multidimensional scaling [MDS]) clássico, para compreender as similaridades e

\footnotetext{
${ }^{2}$ Em outubro de 2017, o Supremo Tribunal Federal (STF) confirmou a decisão da Assembleia Legislativa do Ceará (AL-CE) de extinguir o Tribunal de Contas dos Municípios do Ceará (TCM-CE), com isso, esse estado passou a contar com o Tribunal de Contas do Estado do Ceará (TCE-CE) para fiscalizar as contas do governo estadual e de todos os municípios dessa unidade federativa. Desse modo, o número de tribunais de contas no Brasil caiu para 33 (O Portal de Notícias da Globo [G1], 2017). Também foi excluído o Tribunal de Contas de Roraima (TCE-RR), por não ter sido possível obter todos os dados necessários.
} 
dissimilaridades entre os TCs. De acordo com Marôco (2014), o MDS é uma técnica exploratória multivariada que possibilita representar de modo parcimonioso, em um sistema dimensional reduzido (mapa perceptual), as proximidades (semelhanças/dessemelhanças) entre sujeitos ou objetos, a partir de um conjunto de atributos multivariados medidos ou percebidos.

Esse autor destaca, ainda, que o MDS tem por objetivo a representação de um conjunto de $n$ objetos a partir de $n(n-1) / 2$ semelhanças ou dessemelhanças (proximidades) entre eles, em um conjunto reduzido de $\mathrm{q} \leq \mathrm{n}-1$ dimensões, de modo que as proximidades entre os objetos no novo plano dimensional se assemelhem ao máximo às proximidades originais.

Para elaborar a matriz de distâncias entre os objetos (TCs), utilizou-se o algoritmo Alternating Least Squares SCALing (ALSCAL), ou mínimos quadrados alternados, em português. O algoritmo ALSCAL é aplicável a dados cuja escala esteja em qualquer nível de mensuração, podendo ser adotado no caso de análise métrica ou não métrica. Adicionalmente, o ALSCAL foi o primeiro algoritmo de aplicação generalizada e uma de suas principais características é atribuir maior importância a grandes dessemelhanças. Tal característica é importante para este estudo, uma vez que, ao usar dados binários e muitos TCs não apresentarem grandes dissimilaridades, a maior importância atribuída às grandes dessemelhanças facilita a visualização no mapa espacial (Marôco, 2014).

Como medida de qualidade dos ajustes do MDS não métrico, por meio do algoritmo ALSCAL, foram usadas as medidas de Stress, que revela o quanto a configuração proposta pelo modelo representa o conjunto de dados, e de RSQ (quadrado do coeficiente de correlação entre as distâncias na configuração espacial e a dissimilaridade - essa medida tem interpretação semelhante ao $\mathrm{R}^{2} \mathrm{de}$ uma regressão), que demonstra o poder explicativo do modelo (Kruskal, 1964). Para o cálculo das distâncias entre os TCs, adotou-se o modelo de distância euclidiana.

TABELA 2 MEDIDAS DE QUALIDADE DA SOLUÇÃO DO MDS PARA 0 STRESS E RSQ

\begin{tabular}{l|ccc}
\hline Stress & Veredicto da solução de MDS & RSQ & Veredicto da solução de RSQ \\
\hline$\geq 0,2$ & Pobre/má & $\geq 0,9$ & Muito bom \\
{$[0,1 ; 0,2[$} & Razoável & {$[0,7 ; 0,9[$} & Bom \\
{$[0,05 ; 0,1[$} & Bom & {$[0,5 ; 0,7[$} & Razoável \\
{$[0,0025 ; 0,05[$} & Excelente & {$[0,3 ; 0,5[$} & Sofrível \\
0 & Perfeito & $<0,3$ & Mau \\
\hline
\end{tabular}

Fonte: Adaptado de Kruskal (1964).

\section{RESULTADOS E ANÁLISES}

\subsection{Visão geral dos tribunais de contas brasileiros após a aplicação do formulário de observação}

Como discutido na metodologia, a medida de avaliação da permeabilidade dos TCs brasileiros foi construída com suporte em 3 perspectivas: a) participação cidadã (Participa); b) transparência da 
atividade de fiscalização (Fiscaliza); e c) transparência dos portais (Portal). Desse modo, a Tabela 3 demonstra o percentual de itens atendidos por cada TC segundo a metodologia adotada nesta pesquisa.

\section{TABELA 3 NÍVEL DE ATENDIMENTO DOS TRIBUNAIS DE CONTAS AOS CRITÉRIOS ANALISADOS POR DIMENSÃO (\%)}

\begin{tabular}{|c|c|c|c|c|c|c|c|c|c|}
\hline \multirow{2}{*}{ TC } & \multicolumn{3}{|c|}{ Perspectiva } & \multirow{2}{*}{ Total } & \multirow{2}{*}{ TC } & \multicolumn{3}{|c|}{ Perspectiva } & \multirow{2}{*}{ Total } \\
\hline & Participa & Fiscaliza & Portal & & & Participa & Fiscaliza & Portal & \\
\hline TCE-AC & 32,1 & 64,3 & 37,5 & 50,0 & TCE-SE & 14,3 & 42,9 & 12,5 & 29,5 \\
\hline TCE-AM & 17,9 & 57,1 & 50,0 & 42,3 & TCDF & 17,9 & 47,6 & 50,0 & 37,2 \\
\hline TCE-AP & 14,3 & 61,9 & 50,0 & 43,6 & TCE-GO & 10,7 & 35,7 & 62,5 & 29,5 \\
\hline TCE-PA & 28,6 & 59,5 & 50,0 & 47,4 & TCMs-GO & 10,7 & 38,1 & 37,5 & 28,2 \\
\hline TCMs-PA & 28,6 & 71,4 & 37,5 & 52,6 & TCE-MT & 28,6 & 54,8 & 37,5 & 43,6 \\
\hline TCE-RO & 35,7 & 42,9 & 50,0 & 41,0 & TCE-MS & 10,7 & 54,8 & 37,5 & 37,2 \\
\hline TCE-TO & 28,6 & 69,0 & 62,5 & 53,8 & TCE-ES & 32,1 & 59,5 & 50,0 & 48,7 \\
\hline TCE-AL & 14,3 & 21,4 & 25,0 & 19,2 & TCE-MG & 35,7 & 47,6 & 50,0 & 43,6 \\
\hline TCE-BA & 25,0 & 54,8 & 62,5 & 44,9 & TCE-RJ & 25,0 & 38,1 & 50,0 & 34,6 \\
\hline TCMs-BA & 14,3 & 31,0 & 37,5 & 25,6 & TCM-RJ & 14,3 & 31,0 & 37,5 & 25,6 \\
\hline TCE-CE & 25,0 & 50,0 & 50,0 & 41,0 & TCE-SP & 21,4 & 50,0 & 50,0 & 39,7 \\
\hline TCE-MA & 10,7 & 38,1 & 25,0 & 26,9 & TCM-SP & 7,1 & 35,7 & 25,0 & 24,4 \\
\hline TCE-PB & 21,4 & 42,9 & 12,5 & 32,1 & TCE-PR & 21,4 & 83,3 & 62,5 & 59,0 \\
\hline TCE-PE & 10,7 & 50,0 & 50,0 & 35,9 & TCE-RS & 21,4 & 50,0 & 62,5 & 41,0 \\
\hline TCE-PI & 10,7 & 31,0 & 62,5 & 26,9 & TCE-SC & 25,0 & 66,7 & 50,0 & 50,0 \\
\hline TCE-RN & 10,7 & 35,7 & 87,5 & 32,1 & TCU & 32,1 & 76,2 & 75,0 & 60,3 \\
\hline
\end{tabular}

Fonte: Elaborada pelos autores.

Notas: Os TCs estão organizados por região do Brasil.

“TCE” significa “Tribunal de Contas do Estado" e é seguido pela sigla do estado ao qual pertence.

“TCM" significa “Tribunal de Contas do Município"; quando acrescido da letra "s”, significa “Tribunal de Contas dos Municípios”, seguido pela sigla do ente da Federação de origem.

“TCU” significa "Tribunal de Contas da União".

E “TCDF” significa "Tribunal de Contas do Distrito Federal".

O TCE-RR foi excluído da amostra por falta de dados nas perspectivas estudadas no período de análise.

Como se observa na Tabela 3, apenas 4 dos 32 TCs apresentaram percentual de conformidade superior a 50\% do total analisado (78 itens), quais sejam: a) TCMs-PA; b) TCE-TO; c) TCE-PR; e d) TCU. Dois TCs apresentaram percentual de conformidade de 50\% (TCE-AC e TCE-SC) do total de itens analisados, relacionados, sobretudo, a informações financeiras e orçamentárias e sobre ministros/ conselheiros, indicando apenas o mero cumprimento da legislação. Os demais TCs apresentaram percentual de conformidade inferior a $50 \%$ do total de itens analisados, indicando que os controladores 
parecem não observar os próprios normativos brasileiros, assumindo o papel de panóptico, ou seja, aquele que tudo vê, mas que não é visto e, portanto, controlado.

Em relação à perspectiva transparência da atividade de fiscalização, dois TCs se destacaram: a) TCU; e b) TCMs-PA. Eles apresentaram conformidade superior a $70 \%$ do total de itens analisados (42 itens), seguidos pelos TCE-SC e TCE-AC, que superaram os $60 \%$ de conformidade em relação ao total de itens analisados. A Tabela 3 evidencia, ainda, que 13 TC, ou seja, 40\% dos TCs analisados, apresentaram percentual de conformidade superior a 50\% do total de itens analisados (42 itens).

Evidencia-se, ainda, que os percentuais de atendimento são bastante heterogêneos e podem advir das próprias práticas de auditoria, que não são padronizadas entre os TCs brasileiros, gerando, inclusive, divergências interpretativas significativas entre os órgãos.

Em relação à transparência dos portais, os TCs ainda estão muito distantes do que se espera desses órgãos de controle. Apesar do destaque do TCE-RN e do TCU, que apresentaram, respectivamente, $87,5 \%$ e $75 \%$ de conformidade aos itens analisados (8 itens), a maioria dos TCs (78\%) não apresentou conformidade superior a 50\%, evidenciando baixo nível de transparência dos portais. Dado que cabe a esses órgãos zelar pela transparência dos entes subnacionais, o exemplo tem sido bem desalentador, visto que, além de não servirem como parâmetro aos poderes que fiscalizam, impedem que o legítimo detentor do poder (o povo) obtenha informações tempestivas e confiáveis para solicitar a justificação e, se necessário, punir os agentes responsáveis, ainda que de modo simbólico.

A baixa transparência limita a participação social e, nessa perspectiva, os TCE-MG e TCE-RO foram aqueles que apresentaram maior conformidade aos itens analisados, com percentual de atendimento de 35,7\% (de 28 itens analisados), seguidos pelo TCE-AC, TCE-ES e TCU, com 32,1\%. A Tabela 3 evidencia, ainda, que, dos 32 TCs analisados, apenas os supracitados apresentaram um percentual de conformidade superior a 30\%, evidenciando baixa participação da sociedade civil nesses órgãos e indicando que o exercício da social accountability é remoto, o que, por sua vez, resulta em baixa democratização dessas instituições.

Apesar da estatística descritiva apresentada permitir inferências sobre a condição da transparência e da participação cidadã nos TCs brasileiros, esses dados não permitem a visualização da proximidade entre eles. Por exemplo, quando olhamos para a perspectiva da participação cidadã, os TCE-AC, TCE-ES e TCU apresentam conformidade de 32,1\%. Entretanto, isso não quer dizer que esses TCs sejam semelhantes, visto haver possibilidades múltiplas de combinações de respostas entre os 28 itens analisados nessa perspectiva.

Visando a facilitar a percepção das semelhanças e dessemelhanças entre os objetos (TCs), apresentam-se, a seguir, os resultados do MDS segundo cada uma das perspectivas adotadas neste trabalho.

\subsection{Mapa perceptual da transparência dos portais}

Nessa perspectiva, que considera a avaliação dos portais dos TCs, a partir da existência do portal, do período de atualização, da navegabilidade, da interatividade e do conteúdo dos portais, observa-se que muitos TCs são semelhantes, dada a grande sobreposição de pontos nos mapas perceptuais. Apesar das semelhanças, identificam-se 5 grupos bem definidos de TCs semelhantes: 
- Grupo 1 - TCDF, TCE-SC, TCE-PA, TCE-PE, TCE-PR, RCE-RS e TCE-PI;

- Grupo 2 - TCE-RJ, TCE-SP, TCE-CE, TEC-ES, TCE-MG e TCE-TO;

- Grupo 3 - TCE-AM, TCE-AP, TCE-MS, TCM-RJ, TCE-AC, TCM-MT, TCM-RJ, TCM-SP, TCMsGO, TCMs-BA e TCMs-PA;

- Grupo 4 - TCE-PB, TCE-SE, TCE-AL e TCE-MA; e

- Grupo 5 - TCE-BA, TCE-GO e TCE-RO.

\section{FIGURA $1 \quad$ MAPA TRIDIMENSIONAL DA PERSPECTIVA TRANSPARÊNCIA DOS PORTAIS}

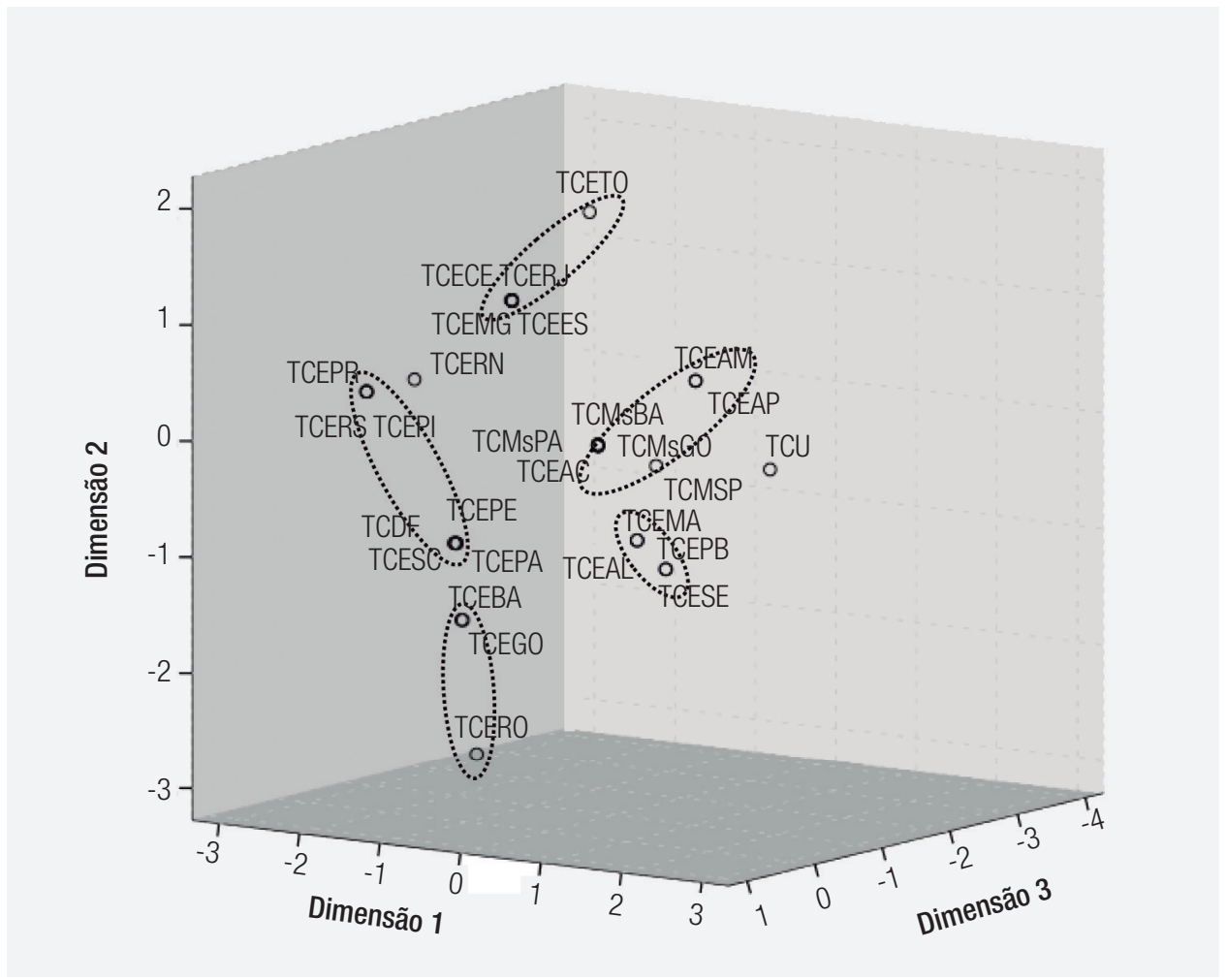

Fonte: Elaborada pelos autores.

Nota: Algum tribunal de contas pode ficar sobreposto e não aparecer na imagem.

Apesar do TCE-RN e do TCU orbitarem em torno dos grupos, eles não se agruparam com nenhum deles quando consideradas duas distâncias euclidiana. Esses TCs apresentaram maior percentual de conformidade nessa perspectiva analítica, com $87,5 \%$ e $75 \%$ de conformidade, respectivamente. Os TCE-BA, TCE-GO e TCE-RO apresentaram percentuais diferentes de conformidade aos itens analisados, mas quando considerados os itens semelhantes que foram respondidos, acabaram agrupando-se.

Apesar dos avanços em relação à transparência de portais do Poder Executivo, no âmbito dos TCs, os resultados evidenciam que muitos deles, além de não atenderem a exigências mínimas de organismos internacionais, não atendem sequer à legislação brasileira. Além disso, as práticas adotadas para a transparência dos portais são diferentes, dificultando o acesso do cidadão, a social accountability, a responsabilização dos agentes públicos e a democratização desses órgãos. 
Registra-se, ainda, que, ao considerar o MDS clássico, com três dimensões, as medidas de veredicto do modelo apresentaram valores de Stress de 0,12794 e RSQ de 0,9185, indicando qualidades de ajuste razoável e muito bom, respectivamente.

\subsection{Mapa perceptual da transparência da atividade de fiscalização}

Essa perspectiva avalia a conformidade de itens relativos ao ciclo de auditoria, a informações sobre os TCs e seus ministros/conselheiros e a informações financeiras e orçamentárias.

Seguindo o padrão da perspectiva anteriormente analisada, essa perspectiva apresentou grande dispersão entre os TCs, dificultando a identificação de grupos. Quando isso é possível (p. ex., quando se juntam TCMs-GO e TCE-PB), o próximo estágio de agrupamento (distância euclidiana) é grande, evidenciando que as práticas de divulgação das atividades de auditoria são muito dissimilares entre os entes. Como não há procedimentos padronizados para a execução de auditorias nos diferentes TCs da Federação brasileira, não é de estranhar que as práticas de divulgação não tenham similaridades.

Acrescenta-se, ainda, que os TCE-SC e TCE-BA foram os mais dissimilares entre todos os TCs e apresentaram similaridades entre si, indicando que, além de serem aqueles que atenderam a mais itens analíticos, os itens analíticos conformes eram semelhantes neles. Apesar de não ser causa, devese destacar que a existência de espaços de coprodução de controle nesses TCs pode favorecer essa proximidade, uma vez que induz à adoção de melhores práticas.

\section{FIGURA 2 MAPA TRIDIMENSIONAL DA PERSPECTIVA TRANSPARÊNCIA DA ATIVIDADE DE} FISCALIZAÇÃO

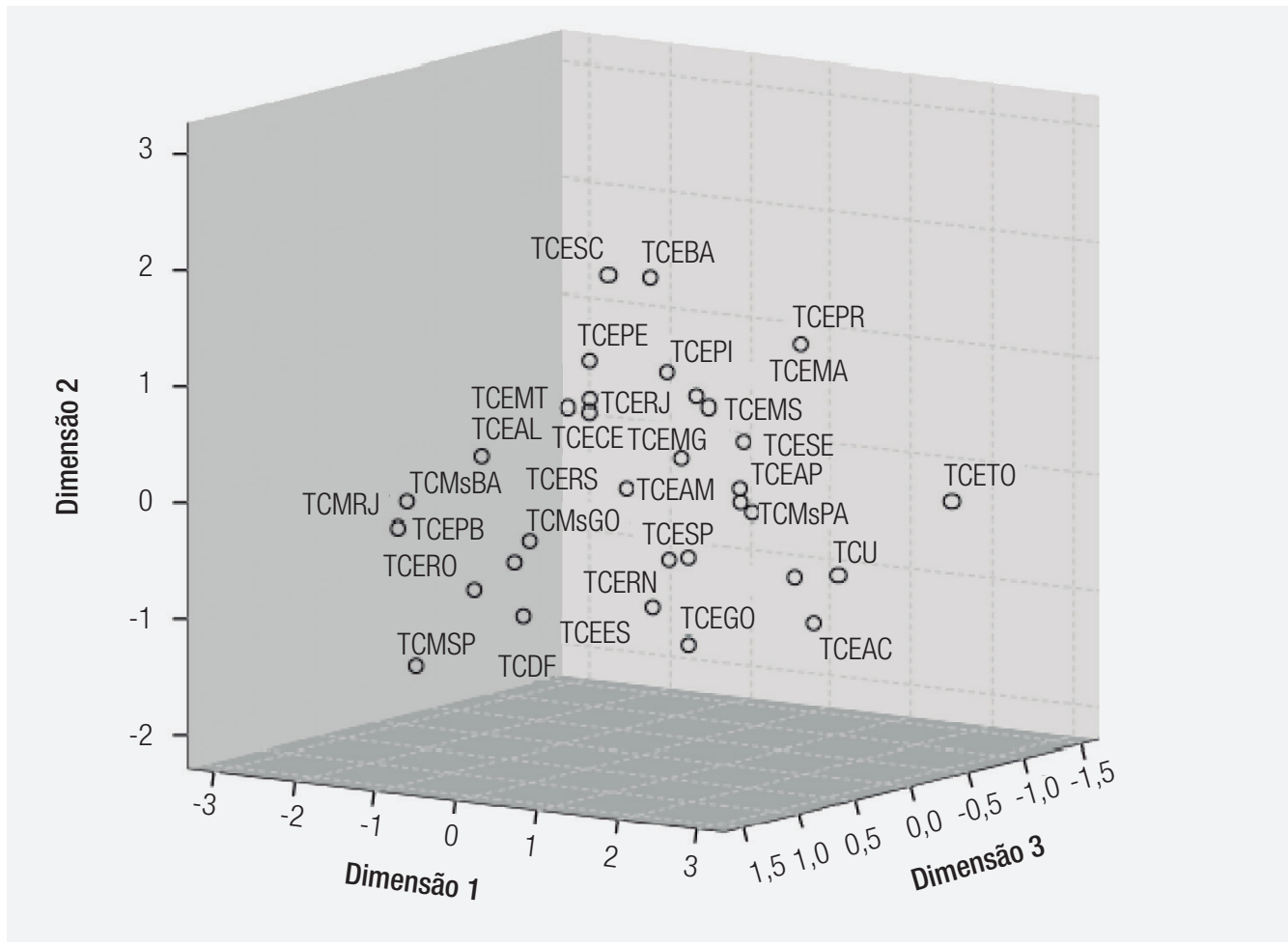

Fonte: Elaborada pelos autores

Nota: Algum tribunal de contas pode ficar sobreposto e não aparecer na imagem. 
Registra-se, ainda, que ao considerar o MDS clássico, com 3 dimensões, as medidas de veredicto do modelo apresentaram valores de Stress de 0,13946 e RSQ de 0,8662, indicando qualidades de ajuste razoável e bom, respectivamente.

\subsection{Mapa perceptual da participação cidadã}

A última perspectiva analisada se refere à participação cidadã, que avalia a abertura dos TCs à participação da sociedade, seja na escolha dos conselheiros, seja na elaboração e no acompanhamento das auditorias, entre outras, e é ilustrada na Figura 3.

\section{FIGURA 3 MAPA TRIDIMENSIONAL DA PERSPECTIVA PARTICIPAÇÃO SOCIAL NOS TRIBUNAIS DE CONTAS BRASILEIROS}

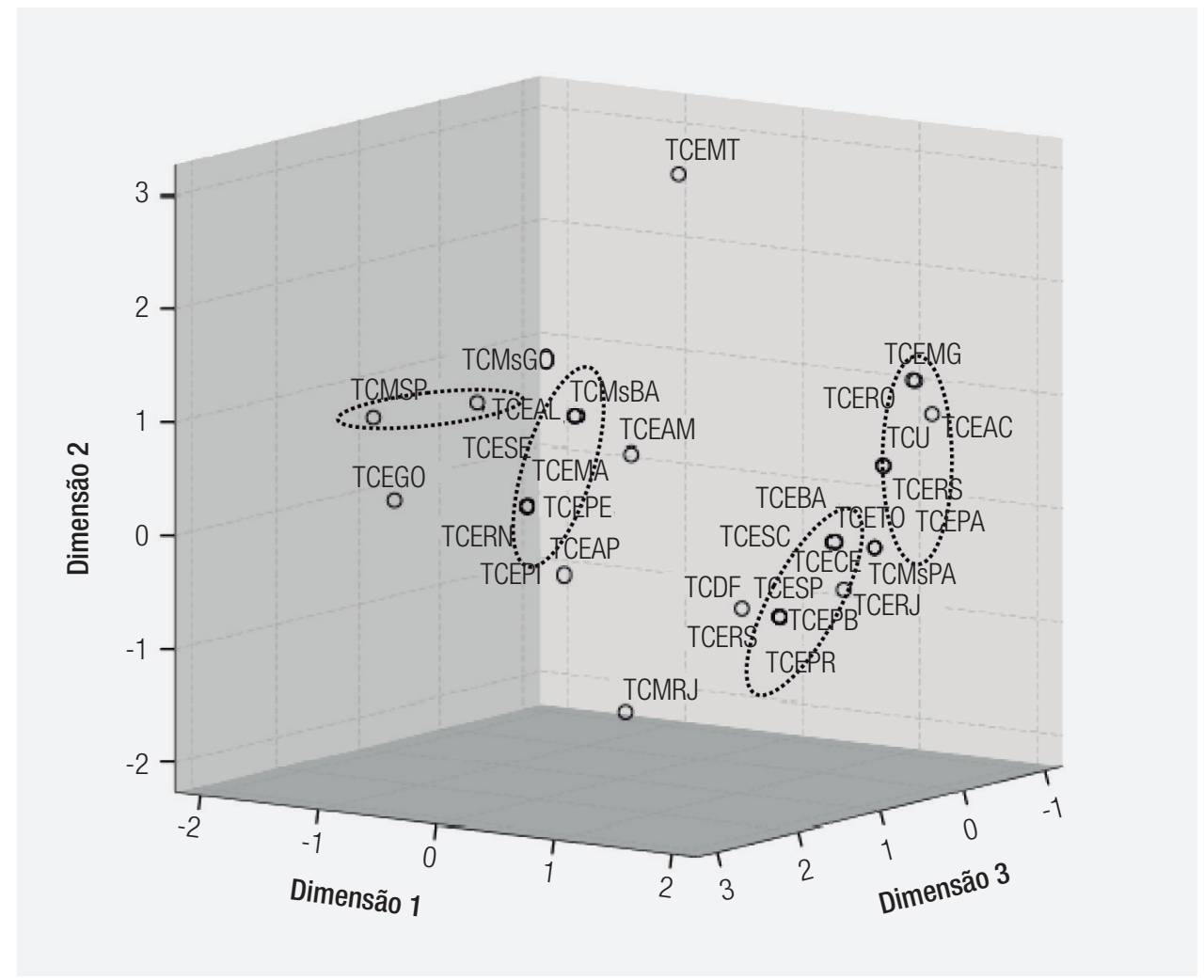

Fonte: Elaborada pelos autores.

Nota: Algum tribunal de contas pode ficar sobreposto e não aparecer na imagem.

Antes de qualquer análise, destaca-se que o modelo dimensional apresentado na Figura 3 atendeu aos valores de veredicto para a solução do MDS, apresentando valores de Stress de 0,08733 e de RSQ de 0,9592 , considerados por Kruskal (1964) bom e muito bom, respectivamente, indicando que o modelo dimensional reduzido apresentado é adequado e pode ser analisado.

Como se observa na Figura 3, o TCE-MG e o TCE-RO são muito semelhantes, visto que o ponto que os representa na escala dimensional está sobreposto. Isso significa que esses $2 \mathrm{TCs}$, que atenderam 
a 35,7\% dos itens analisados nessa perspectiva analítica, atenderam a itens de análise semelhantes. O TCE-AC e o TCE-ES, apesar de apresentarem percentuais de conformidade iguais (32,1\%), não se apresentam em um plano comum no mapa perceptual, indicando que, apesar de próximos, eles não atenderam aos mesmos itens analisados, diferente do que ocorre com os TCE-ES e TCU.

A partir da distância euclidiana, o mapa perceptual identificou 4 grupos mais semelhantes entre si e, consequentemente, mais dessemelhantes dos demais, a saber:

- Grupo 1 - TCMs-PA, TCE-TO, TCE-PA, TCE-RJ, TCE-RO, TCE-MG, TCU, TCE-ES e TCE-AC;

- Grupo 2 - TCE-CE, TCE-SC, TCE-BA, TCE-PR, TCE-RS, TCE-PB, TCE-SP e TCDF;

- Grupo 3 - TCM-SP e TCMs-GO;

- Grupo 4 - TCE-RN, TCE-MS, TCE-MA, TCE-PE, TCE-PI, TCE-AP, TCMs-BA, TCE-SE, TCE-AL e TCE-AM.

Destaca-se, adicionalmente, que os TCE-MT, TC-GO e TCM-RJ foram aqueles que apresentaram maior dissimilaridade e, por isso, acabaram orbitando próximo aos grupos, sem tomar parte em nenhum deles.

Quando se combina o mapa perceptual apresentado com a estatística descritiva dos dados, verificase que, apesar de muitos TCs apresentarem percentuais iguais de conformidade aos itens analisados, eles não são necessariamente iguais, visto que os itens analíticos conformes podem variar. Assim, o que se vê é que, além de não desenvolverem mecanismos para a participação social, as poucas práticas nesse sentido são diferentes entre os TCs, evidenciando uma autonomia, mas também uma descoordenação de procedimentos entre esses órgãos.

Em suma, no que concerne à participação cidadã, pode-se dizer que, de maneira geral, os TCs têm fraco nível de permeabilidade à sociedade, isto é, são instituições ainda insuladas e, consequentemente, pouco democratizadas. Embora haja cada vez mais apelo por mais espaços de participação, nenhum TC brasileiro oferece oportunidade ou mecanismo para que a sociedade possa participar efetivamente: a) no processo de designação de ministros/conselheiros; b) no processo de elaboração do plano de auditoria ou mesmo de participação durante a realização das auditorias; e c) no acompanhamento do cumprimento pelos gestores públicos das determinações e recomendações. Quando se olha para os canais ou mecanismos de interlocução com a sociedade, basicamente, eles se restringem à ouvidoria.

Observa-se que, apesar do discurso predominante ser o de incentivo à participação social, ao se considerar os 3 mapas perceptuais é possível constatar que o desenvolvimento institucional dos TCs brasileiros é incremental, corroborando o entendimento de Loureiro et al. (2008) e Rocha e Zuccolotto (2017). Mesmo que não exista nenhum impedimento legal para a promoção da transparência e de espaços de participação, parece haver forte resistência por parte desses órgãos, tornando-se uma espécie de panóptico da modernidade, ou seja, aquele que está autorizado a tudo ver, mas que não gosta de ser visto. A não transparência dessas instituições, nos termos de Birkinshaw (2006), faz com que haja um triplo impacto na construção da accountability: a) impede ou dificulta o cidadão, particularmente ou em grupo, de exercer controle sobre as instituições do Estado (sobre o poder); b) não permite a interação sociedade civil-Estado para a coprodução de bens, controle e informação; e c) mitiga a contribuição que os TCs podem prestar para o aperfeiçoamento democrático (Bovens et al., 2014; O’Donnell, 1998; Przeworski et al., 1999). 


\section{CONSIDERAÇ̃̃ES FINAIS}

Desde o século XIX, Weber (2012) percebeu que a relação entre política e burocracia era marcada por uma tensão constante, uma vez que a burocracia pública, devido ao seu conhecimento técnico, concentrava muito poder e isso poderia ameaçar a democracia, dado que os burocratas, dentro de um padrão de dominação racional-legal, buscariam aumentá-lo, usando como arma a manutenção do segredo sobre seus conhecimentos e suas intenções. Ao concentrar poder e não se expor aos controles dos políticos eleitos e, sobretudo, da sociedade, a burocracia rompe a relação circular que conecta Estado e sociedade nas democracias representativas.

Nessa perspectiva, os TCs brasileiros, devido às suas características burocráticas e sua composição secular, tornaram-se objeto deste estudo, cujo objetivo foi analisar a permeabilidade dos TCs brasileiros à sociedade, por meio da análise da transparência dos portais desses órgãos, da transparência da atividade de fiscalização e dos mecanismos existentes para a participação cidadã nesses órgãos. Apesar dos termos transparência e controle social (social accountability) estarem em evidência nos discursos de ministros e conselheiros dos TCs, os resultados indicam que eles ainda são insulados, dado que, em geral, são pouco transparentes e não adotam práticas de estímulo ao controle social.

Em relação à participação cidadã, constatou-se que os TCs têm fraco nível de permeabilidade à sociedade, isto é, são instituições ainda insuladas e, consequentemente, pouco democratizadas. Embora haja cada vez mais apelo por mais espaços de participação, nenhum TC brasileiro oferece mecanismo para que a sociedade possa participar efetivamente: a) no processo de designação de ministros/conselheiros; no b) processo de elaboração do plano de auditoria ou durante a realização das auditorias; e c) no acompanhamento do cumprimento pelos gestores públicos das determinações e recomendações. Quando se olha para os canais ou mecanismos de interlocução com a sociedade, basicamente, eles se restringem à ouvidoria.

Logo, quando é para se expor, basicamente os TCs brasileiros cumprem, ainda que de maneira incompleta, as prescrições normativas previstas na LRF e na LAI. Portanto, em termos de accountability, os TCs ainda não permitem o acompanhamento amplo e fácil das ações que empreendem. Isso, sem dúvida, impede, ou ao menos dificulta, o monitoramento do comportamento dessas instituições pelo controle social e, por consequência, pode retardar, se não inviabilizar, ações tendentes a expor e denunciar atos ilegais praticados por essas instituições, ou mesmo ativar as operações de outras agências horizontais de controle, como dispõem Peruzzotti e Smulovitz (2002).

Apesar do cenário não ser favorável, avanços incrementais podem ser constatados quando se trata de mecanismos de estímulo à participação cidadã. 32 TCs analisados, 15 têm uma página, aba ou guia na internet dedicada especificamente à cidadania, ainda que tais espaços compreendam informações dispersas e pouco estruturadas, demandando do cidadão ou do interessado na informação uma razoável quantidade de tempo para encontrá-las. Além disso, pode-se observar a existência, em alguns tribunais, de iniciativas relacionadas à coprodução do controle, tais como ouvidorias itinerantes e audiências públicas.

Por meio do roteiro de conformidade, também foi possível identificar que todos os TCs têm uma estrutura institucional de ensino ou treinamento. Esse mecanismo se mostra importante, na medida em que o TC poderia atuar capacitando a cidadania para a realização de controle mais eficaz. Entretanto, nem todos os TCs oferecem cursos ou palestras à sociedade. Na maior parte dos casos, tais cursos são oferecidos para capacitação de seus próprios servidores e dos gestores públicos do 
Poder Executivo. Registra-se, todavia, que 9 dos TCs avaliados oferecem cursos de capacitação aos conselhos de políticas públicas.

Quando se trata de canais ou mecanismos de interlocução com a sociedade, constatou-se que a ouvidoria, física e via internet, o portal da transparência e o serviço de informação ao cidadão são os principais meios utilizados pelos TCs para interlocução com a sociedade. Contudo, também se identificou, em 3 TCs: a) a realização de debate/diálogo público; e b) a existência de canal de rádio ou televisão on-line. Mesmo nesses, em poucos casos os programas são utilizados para veicular e discutir com a sociedade o resultado das ações empreendidas pelos TCs. Em grande parte, tais programas são utilizados quase que exclusivamente para transmitir as seções realizadas pelos TCs.

Já em relação à divulgação dos resultados das ações empreendidas pelos TCs, constatou-se que, de modo geral, os TCs não divulgam as contas apresentadas pelos gestores públicos em suas respectivas páginas na internet. Mesmo dentre os poucos que disponibilizam, não é tarefa fácil acessar essas contas. Isso também vale para: a) a disponibilização e o acesso ao parecer prévio sobre as contas do governo; b) a disponibilização e o acesso à relação dos agentes condenados pelo mau uso de recursos públicos; e c) os resultados das auditorias. Constatou-se, ainda: a) a incompletude das informações disponibilizadas; b) a baixa compreensibilidade das informações; e c) as restrições de meios para divulgá-las.

Realizando uma análise conjunta das 3 perspectivas, constata-se que os TCs brasileiros, de modo geral, ainda estão distantes da permeabilidade desejada para que o controle social se mostre mais efetivo em seu papel fiscalizador, limitando o exercício continuado da accountability para além do momento do voto (Urbinati, 2006). Fica evidenciada, também, a fragilidade dos mecanismos de auxílio ou de facilitação do exercício do controle social sobre a administração pública. Esse quadro evidencia que, apesar dos avanços institucionais destacados por Loureiro et al. (2008) e Rocha e Zuccolotto (2017), quando se trata de democratizar essas instituições, parece haver pouca vontade política, indicando o que Weber (2012) já apontava como uma ameaça à democracia, dado que, além de concentrar muito poder, tais instituições preferem manter segredo sobre suas ações e não se submeter nem ao controle político nem ao controle da sociedade.

Assim, os TCs permanecem distantes ou mesmo insulados da sociedade e isso não traz benefícios nem para essas instituições nem para a sociedade, já que a possibilidade de diminuir a assimetria informacional entre representantes-representados acaba se tornando um horizonte ainda longo a ser trilhado. Esse quadro reforça a necessidade de revisão do desenho institucional dos TCs brasileiros, fazendo com que, além de ser uma entidade de accountability horizontal, também possa ser accountable, permitindo o controle parlamentar sobre suas ações e, sobretudo, o controle da sociedade.

Contudo, deve-se ressaltar que, apesar do cenário desfavorável quando se trata da democratização dos TCs, deve-se ter em mente que em, 30 anos de redemocratização, ocorreram avanços, sobretudo por conta da CF (1988), da LRF e da LAI, as quais constituem pedras angulares que têm fundamentado o caminho para a democratização desses órgãos e que possibilitaram a realização desta pesquisa. É claro que essas instituições ainda têm muito a avançar, mas a mera incorporação da transparência e do controle social no discurso de tais instituições de controle já cria um ambiente favorável para a implementação de ações que podem resultar em avanços democráticos.

Além disso, apesar de haver forças de resistência nessa burocracia pública, muitas das mudanças e dos avanços ocorridos nos TCs decorrem da própria resiliência de parte dessa burocracia (Loureiro 
RAP | Insulados e não democráticos: a (im)possibilidade do exercício da social accountability nos Tribunais de Contas brasileiros

et al., 2008), indicando que características patrimonialistas e clientelistas convivem com forças inovadoras e transformadoras dessas estruturas.

Por fim, deve-se ter em mente que esta pesquisa se limitou a analisar os portais dessas instituições e, a partir daí, compreender os espaços de participação social e de social accountability existentes. Por isso, recomenda-se, para futuras pesquisas, que sejam realizadas entrevistas com conselheiros e servidores para compreender como esses atores interpretam a necessidade de transformação democrática de tais órgãos e quais ações têm sido tomadas, se é que têm sido, nesse sentido. 


\section{REFERÊNCIAS}

Arantes, R. B., Loureiro, M. R., Couto, C., \& Teixeira, M. A. C. (2010). Controles democráticos sobre a administração pública no Brasil. In M. R. Loureiro, F. L. Abrucio, \& R. S. Pacheco (Eds.), Burocracia e política no Brasil: desafios para a ordem democrática no século XXI (pp. 109-147). Rio de Janeiro, RJ: Ed. FGV.

Bentham, J. (2008). O panóptico (2a ed.). Belo Horizonte, MG: Autêntica.

Birkinshaw, P. (2006). Freedom of information and openness: fundamental human rights. Administrative Law Review, 58(1), 177-218.

Bobbio, N. (2000). Teoria geral da politica: a filosofia politica e as lições dos classicos. Rio de Janeiro, RJ: Campus.

Bovens, M., Goodin, R. E., \& Schillemans, T. (2014). The Oxford handbook of public accountability. Oxford, England: Oxford University Press.

Cavalcante, P., \& Lotta, G. (2015). Burocracia de médio escalão: perfil, trajetória e atuação. Brasília, DF: Escola Nacional de Administração Pública.

Condorcet, M. J. A. N. D. (1968). Oeuvres: nouvelle impression en fac-similé de lédition (Paris 1847-1849). Stuttgart, Deutschland: Friedrich Frommann.

Constituição da República Federativa do Brasil, de 5 de outubro de 1988. (1988). Brasília, DF.

Corporation for Digital Scholarship. (n.d.). Zotero (Software). Recuperado de https://www.zotero.org/ International Budget PartnerShip. (2015). Open Budget Survey 2015. Recuperado de http://www. internationalbudget.org/wp-content/uploads/ OBS2015-Report-English.pdf

International Organization of Supreme Audit Institutions. (1977). La Declaración de Lima. Recuperado de http://es.issai.org/media/14482/ issai_1s.pdf

Kruskal, J. B. (1964). Multidimensional scaling by optimizing goodness of fit to a nonmetric hypothesis. Psychometrika, 29(1), 1-27.

Loureiro, M. R., Abrucio, F. L., \& Pacheco, R. S. (2010). Burocracia e política no Brasil: desafios para a ordem democrática no século XXI. Rio de Janeiro, RJ: Ed. FGV.
Loureiro, M. R., Teixeira, M. A. C., \& Moraes, T. C. (2009). Democratização e reforma do Estado: o desenvolvimento institucional dos tribunais de contas no Brasil recente. Revista de Administração Pública, 43(4), 739-772.

Loureiro, M. R., Teixeira, M. A. C., \& Prado, O. (2008). Construção de instituições democráticas no Brasil contemporâneo: transparência das contas públicas. Organizações \& Sociedade, 15(47), 107-119.

Manin, B. (1997). The principles of representative government. Cambridge, England: Cambridge University Press.

Marôco, J. (2014). Análise estatística com utilização do SPSS (6th ed.). Lisboa, Portugal: Sílabo.

Marschall, M. J. (2004). Citizen participation and the neighborhood context: a new look at the coproduction of local public goods. Political Research Quarterly, 57(2), 231-244.

Michels, R. (1915). Political parties. Ontario, Canada: Batoche.

Mosca, G. (1980). The ruling class. Westport, CT: Greenwood Press.

O’Donnell, G. (1998). Accountability horizontal e novas poliarquias. Lua Nova, 44, 27-54.

Olivieri, C. (2011). Os controles políticos sobre a burocracia. Revista de Administração Pública, 45(5), 1395-1424.

O Portal de Notícias da Globo. (2017, 26 de outubro). STF mantém extinção do Tribunal de Contas dos Municípios do Ceará. Recuperado de https:// gl.globo.com/ceara/noticia/stf-mantem-extincaodo-tribunal-de-contas-dos-municipios-do-ceara. ghtml

Organización Latinoamericana y del Caribe de Entidades Fiscalizadoras Superiores. (2014). Guía para la implementación de los principios sobre Rendición de Cuentas de la Declaración de Asunción. Recuperado de http://www.olacefs.com/wp-content/ uploads/2014/10/7.3.31.pdf

Paine, T. (2011). Rights of man. Peterborough, Canada: Broadview Press.

Pareto, V. (1979). The rise and fall of elites. New York, NY: Arno Press. 
Peruzzotti, E., \& Smulovitz, C. (2002). Accountability social: la otra cara del control. In E. Peruzzotti, \& C. Smulovitz (Eds.), Controlando la política. Ciudadanos y medios en las democracias latinoamericanas (pp. 23-52). Buenos Aires, Argentina: Tema.

Pitkin, H. F. (1967). The concept of representation. Berkeley, CA: University of California Press.

Przeworski, A., Stokes, S. C., \& Manin, B. (1999). Democracy accountability and representation. Cambridge, England: Cambridge University Press.

Rocha, D. G. (2017). As duas faces de Jano dos tribunais de contas brasileiros no auxílio ao exercício do controle social sobre a administração pública (Tese de Doutorado). Fundação Getulio Vargas, São Paulo, SP.

Rocha, D. G., \& Zuccolotto, R. (2017). A modernização dos tribunais de contas do Brasil: avaliação da implantação do PROMOEX nos tribunais de contas subnacionais. Enfoque: Reflexão Contábil, 36(3), 70-88.
Schedler, A. (1999). Conceptualizing accountability. In A. Schedler, L. Diamond, \& M. F. Plattner (Eds.), The self-restraining State. Power and accountability in new democracies. (pp. 13-28). London, England: Lynne Rienner.

Schumpeter, J. A. (1961). Capitalismo, socialismo y democracia. Madrid, España: Aguilar.

Urbinati, N. (2006). O que torna a representação democrática? Lua Nova: Revista de Cultura e Política, 67, 191-228.

Weber, M. (2011). Ciência e política: duas vocações. São Paulo, SP: Cultrix.

Weber, M. (2012). Economia e sociedade: fundamentos da sociologia compreensiva (4a ed.). Brasília, DF: Ed. UnB.

Zuccolotto, R., \& Teixeira, M. A. C. (2019). Transparência: aspectos conceituais e avanços no contexto brasileiro. Brasília, DF: Escola Nacional de Administração Pública.

\section{Diones Gomes da Rocha}

https://orcid.org/0000-0002-2346-9464

Doutor em Administração Pública e Governo; Auditor do Tribunal de Contas da União; Pós-doutorando no Programa de Pós-graduação em Contabilidade da Universidade Federal do Espírito Santo (UFES). E-mail: dionesgr222@hotmail.com

\section{Robson Zuccolotto}

https://orcid.org/0000-0002-2629-5586

Pós doutor em Administração Pública e Governo; Professor do Programa de Pós-Graduação em Ciências Contábeis da Universidade Federal do Espírito Santo (UFES). E-mail: robsonzuccolotto@gmail.com

\section{Marco Antonio Carvalho Teixeira}

https://orcid.org/0000-0003-3298-8183

Doutor em Ciências Sociais pela Pontifícia Universidade Católica de São Paulo (PUC-SP); Professor-adjunto e pesquisador do Departamento de Gestão Pública na Escola de Administração e de Empresas da Fundação Getulio Vargas de São Paulo (FGV EAESP). E-mail: marco.teixeira@fgv.br 